\title{
Journey from first name to last name: Pursuing my dream
}

\section{Siva Sundeep Koppolu, MBBS}

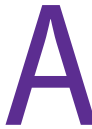
fter graduating from medical school in India, where I was born and raised, I came to the United States in 2009 to expand my medical knowledge. At that time, I completed my clinical skills exam and soon after began a volunteer rotation at New York-Presbyterian Queens Hospital. In those early days, as I made my rounds through the emergency department (ED) of the hospital, I would introduce myself as Dr. Siva, which is my first name; this is how the doctors back home in India would introduce themselves to patients. Little did I know that the same name convention was not necessarily used here in the United States. Nonetheless, in those formative days, I learned a great deal from listening to the unique stories of how my patients had ended up in the ED, and I quickly felt right at home getting to know them.

When I first came to the United States, I had limited knowledge of psychiatry because I had only had a few months of psychiatry rotations during medical school. But in 2012, while I served as a volunteer in a research and observership program at Beth Israel Medical Center, one of my colleagues who was a psychiatry resident piqued my interest in the specialty and motivated me to explore and learn more about the various treatment modalities, strategies, and nuances this new modern world of psychiatry had to offer.

So I began by attending training sessions and evening seminars at the New York Psychoanalytic Society \& Institute, where I became interested in Sigmund Freud's work on the development of psychoanalysis.

From there, my appetite for knowledge only continued to grow, and I took every opportunity to participate in various learning exercises, present at poster sessions, and give lectures at national conferences. I read and absorbed significant theories and texts and interacted with and learned from colleagues and mentors as I strived to sculpt my mind, with the aim of becoming a wellrounded psychiatrist.

\section{Overcoming challenges}

As I worked to further my understanding of psychiatry and understand the different treatment modalities-my goals becoming more clear with each step of my journeyI faced a significant setback. I was unable to secure a residency position to officially enter the specialty. I was devastated in my pursuit to realize the American Dream. At that point, I had been in the United States for 4 years with the financial and emotional support of my parents back home in India. I continued to struggle; another 2 years passed, and I was still coming up empty in my search for a residency position.

In the meantime, I kept moving forward, with my sights firmly on learning more about psychiatry. This time, I sought

LET YOUR VOICE BE HEARD

CURRENT PsyChIATRY invites psychiatry residents to share their views on professional or clinical topics for publication in Residents' Voices. E-mail jbauer@mdedge.com for author guidelines.

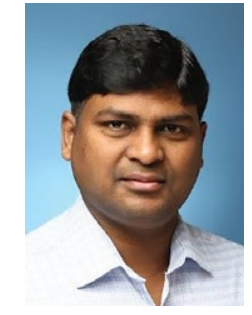

Dr. Koppolu is a Neuromodulation Fellow, Department of Psychiatry, University of Florida College of Medicine, Gainesville, Florida.

\section{Disclosure}

The author reports no financial relationships with any companies whose products are mentioned in this article, or with manufacturers of competing products.

doi: $10.12788 / c p .0041$ 
Clinical Point

\section{My educational journey in a place far from home has impacted me in ways $I$ never knew possible}

out several projects, including one where I served as a research assistant (volunteer) for nonpharmacologic clinical trials in patients with bipolar disorder, and another where I served as a research assistant (volunteer) at a substance use disorder clinic at Columbia University. I was also accepted into the "Prelude to Training" program at the Psychoanalytic Association of New York, which is affiliated with the NYU Grossman School of Medicine. Through that program, I was introduced to psychodynamic thinking and practice, which gave me the valuable foundation of thinking beyond oneself.

\section{Grit and determination}

To further my education, I studied clinical and translational sciences at Creighton University in Omaha. I was given opportunities to discuss topics related to the historical aspects of and recent advances in psychoanalysis through my involvement with the Professional Reading Alliance on Psychoanalysis at The Circle for the Lacanian Orientation of Omaha. Then came the moment when all my dreams came to fruition-I was accepted into the psychiatry residency program at Creighton University.

Those 4 years of residency passed by in a flash! Recently, I began a neuromodulation fellowship at the University of Florida in Gainesville. Here, my journey continues, as I search for tools to help the disenfranchised and those in need of mental health support. After the neuromodulation fellowship, I plan to pursue a pain medicine fellowship.

Through the years, I have grown both professionally and personally. I have also overcome the instinctual urge to introduce myself to patients by my first name and have adapted to the American style of using my last name, and now introduce myself as Dr. Koppolu.

My educational journey in a place far from home has impacted me in ways I never knew possible, and I believe my strength to continue the pursuit is rooted in my passion and ambition to become a psychiatrist. I never gave up working toward that dream-a dream that is slowly becoming a reality. 